\title{
Notes on Eggs and Hatchlings of the Oriental Garden Lizard, Calotes versicolor (Daudin 1802), and the Common House Gecko, Hemidactylus frenatus (Schlegel 1836) in Gujarat, India
}

Dikansh S. Parmar

Department of Zoology, Goa University, Taleigão Plateau, Goa, India (ophiophagus_hannah10@yahoo.com)

Photographs by the author.

$\mathrm{H}$ erein I describe eggs and hatchlings of two species of reptiles commonly encountered in Gujarat, India. The Oriental Garden Lizard (Calotes versicolor) is an agamid lizard that is widely distributed in India (Das 2016; Parmar and Tank 2019; Fig. 1). Sometimes called "bloodsuckers" because of the red head, shoulders, forelegs, and throat of breeding males, these medium-sized arboreal diurnally active lizards with oval heads and laterally compressed bodies inhabit gar-

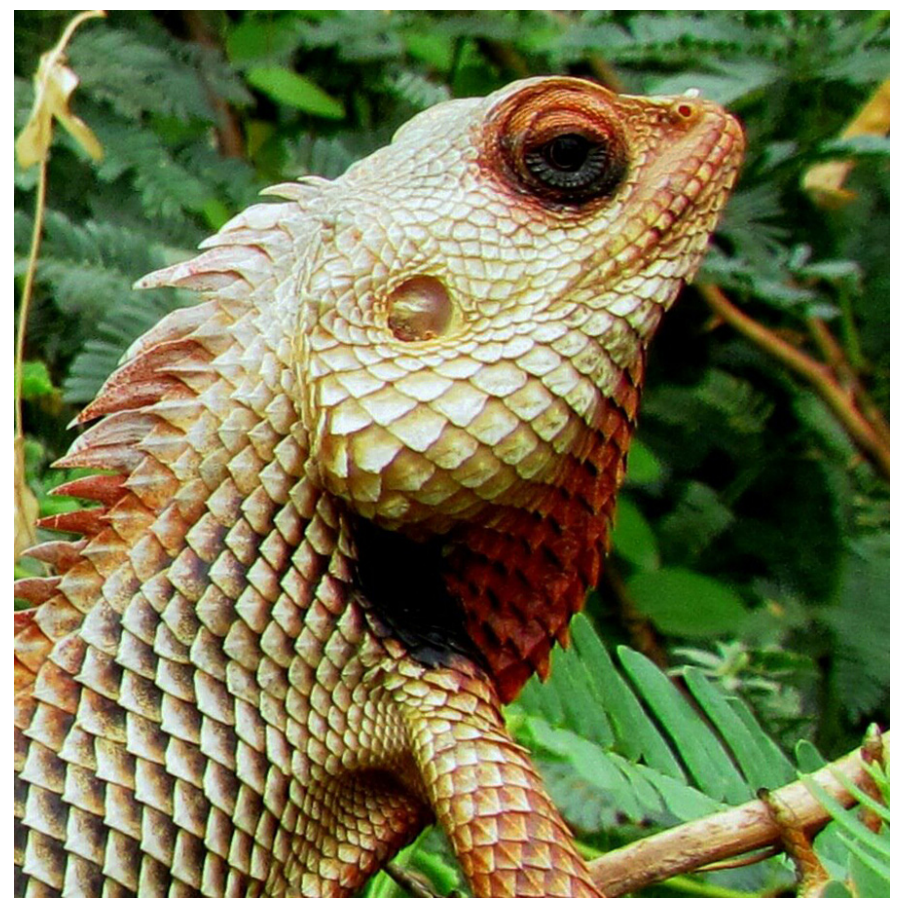

Fig. 1. The Oriental Garden Lizard (Calotes versicolor) is frequently encountered in India.

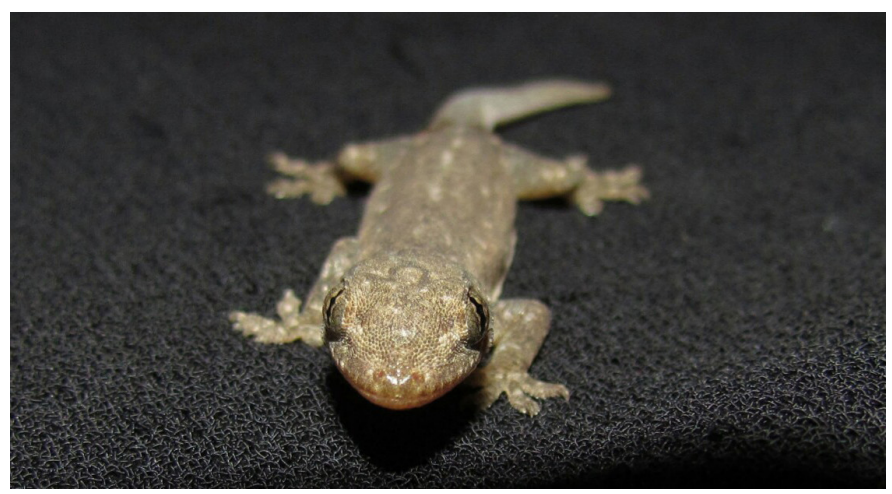

Fig. 2. The Common House Gecko (Hemidactylus frenatus) is widely distributed in India.

dens, hedges, scrublands, and forests (Daniel 1983, 2002). Females lay 11-23 eggs in self-excavated soil burrows (Parmar and Tank 2019). The Common House Gecko (Hemidactylus frenatus), native to southern and southeastern Asia, is widely distributed in India (Daniel 1983, 2002; Fig. 2) and has spread far beyond its natural range due to human introductions (e.g., Das et al. 2008). These nocturnal geckos, which generally hide during the day, occur naturally in trees but have adapted well to buildings in populated areas. Females typically lay two eggs in crevices (Parmar and Tank 2019).

At $1020 \mathrm{~h}$ on 8 July 2012, I found nine eggs in the garden of my home $\left(21.1685^{\circ} \mathrm{N}, 72.7931^{\circ} \mathrm{E}\right)$. Given the shape and size of the eggs $(19 \times 13 \mathrm{~mm})$, they were clearly not those of a snake. I left the eggs undisturbed but monitored them every morning and evening. Twenty-four days later on 1 August, I found two hatchling Oriental Garden Lizards. Most of the hatchlings had left but two more were about to 


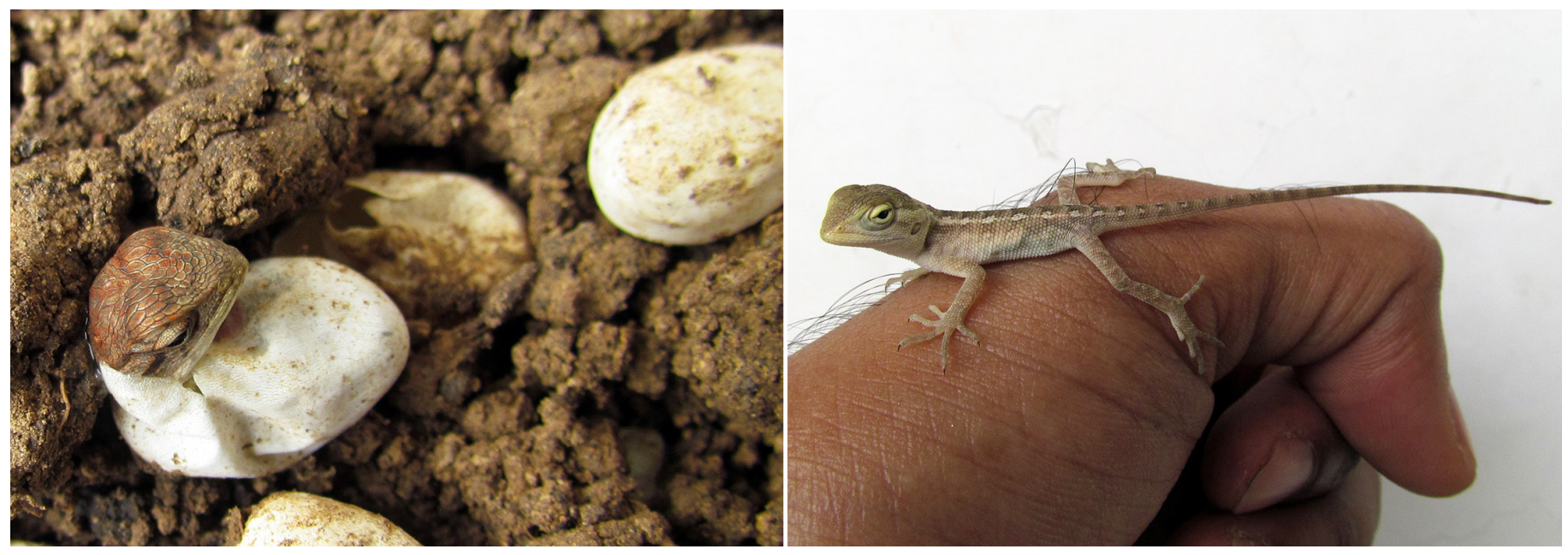

Fig. 3. Hatchling Oriental Garden Lizard (Calotes versicolor) emerging from the egg (left) and shortly after hatching (right).

hatch. The average temperature that day was $28^{\circ} \mathrm{C}$. I placed the eggs and empty shells in a plastic bowl filled with soil and brought it inside to photograph the emerging hatchlings (Fig. 3), which measured $23 \mathrm{~mm}$ snout-vent length (SVL) and $52 \mathrm{~mm}$ total length (TL). I released the healthy hatchlings in the garden.

At 1219 h on 30 May 2018, while surveying an area with approximately 70 trees (Fig. 4) on the grounds of the Veer Narmad South Gujarat University in Nakshatra Van $\left(21.151^{\circ} \mathrm{N}, 72.785^{\circ} \mathrm{E}\right)$, I captured an adult Common House Gecko on a tree and found two gecko eggs in a crevice behind the bark of another tree (Fig. 5). I pried open the bark and marked the upper side of the eggs with a pen before carefully removing them from the crevice. The first egg measured 8.5 x $7.5 \mathrm{~mm}$ and weighed $0.24 \mathrm{~g}$, the second egg $8.2 \times 7.2 \mathrm{~mm}$ and $0.21 \mathrm{~g}$. I placed them in a plastic box filled with vermiculite and sprayed them with water at four-day intervals. Endof-summer temperatures in this part of India average around $33^{\circ} \mathrm{C}$. After 10 days, at $0930 \mathrm{~h}$ on 10 June 2018, I found a hatchling that had emerged from the first egg. It measured $20 \mathrm{~mm} \mathrm{SVL}$ and $38 \mathrm{~mm}$ total length TL and weighed $0.17 \mathrm{~g}$.

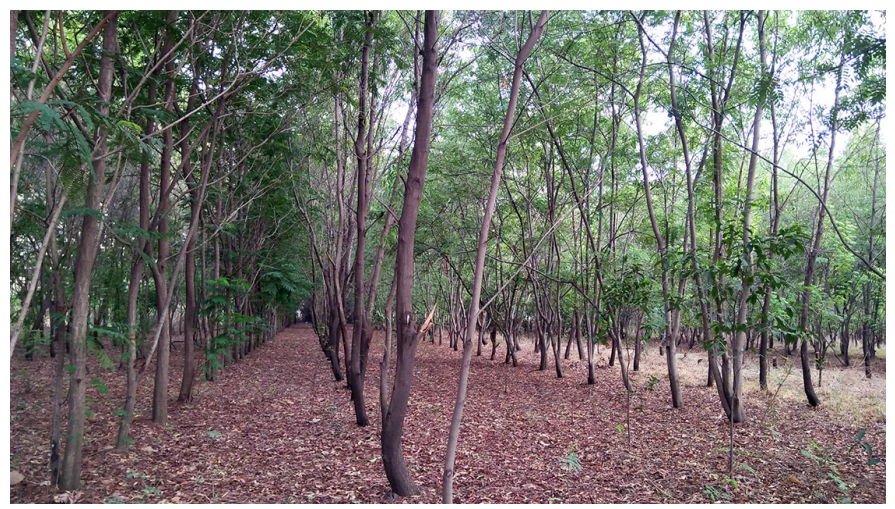

Fig. 4. Nakshatra Van, a planted area on the grounds of the Veer Narmad South Gujarat University, where an adult and eggs of the Common House Gecko (Hemidactylus frenatus) were found.

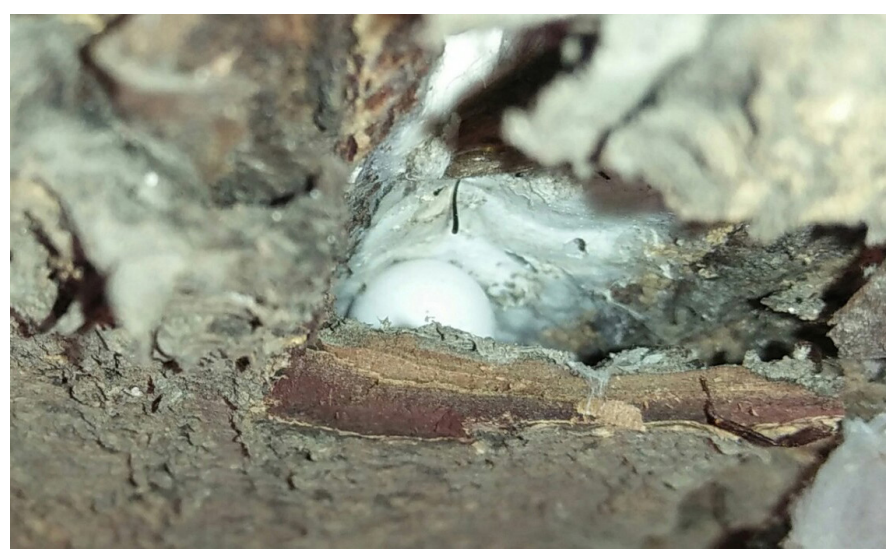

Fig. 5. Two eggs of the Common House Gecko (Hemidactylus frenatus) in a crevice under bark at Nakshatra Van.

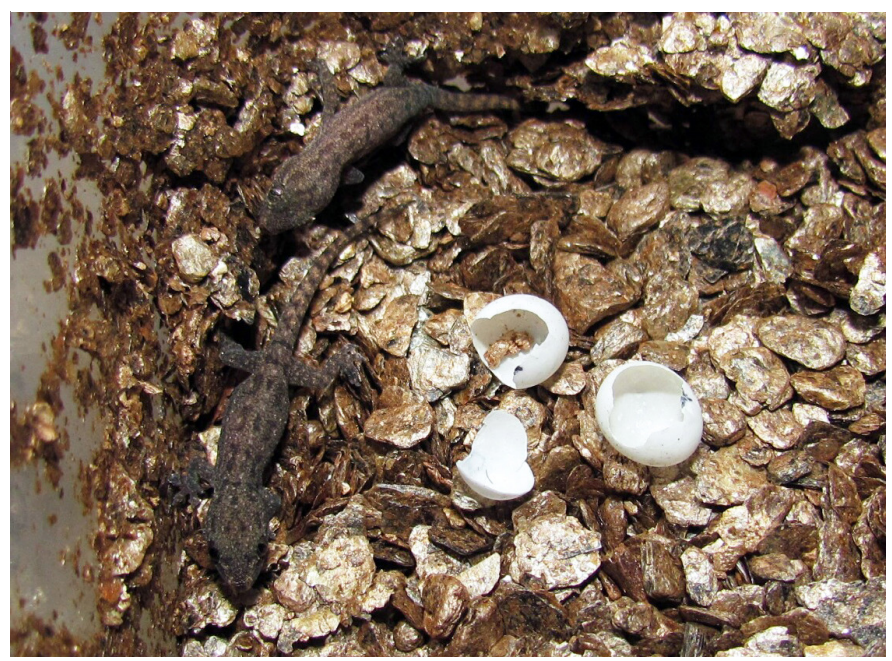

Fig. 6. Hatchling Common House Geckos (Hemidactylus frenatus).

The second hatchling emerged at $1445 \mathrm{~h}$ that same day. It measured $18 \mathrm{~mm} \mathrm{SVL}$ and $31 \mathrm{~mm} \mathrm{TL}$ and weighed $0.16 \mathrm{~g}$.

The two hatchlings (Fig. 6) initially tried to escape but when caught and no longer able to flee they would feign death 


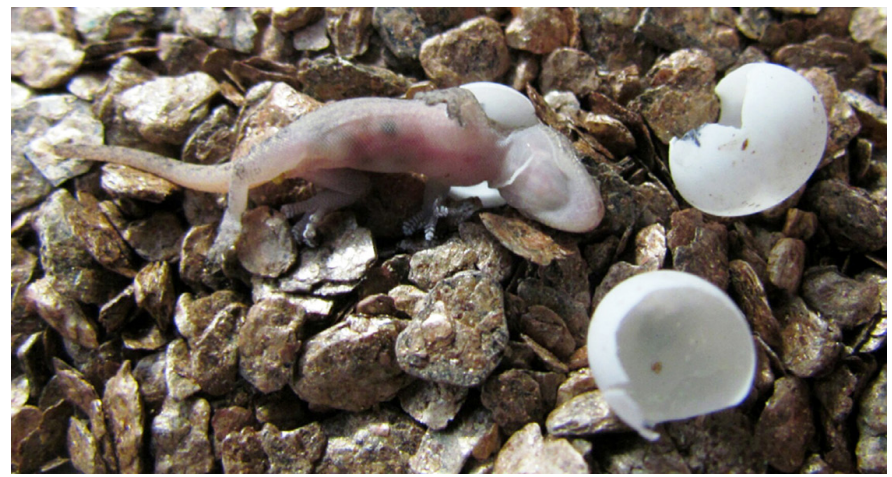

Fig. 7. A hatchling Common House Gecko (Hemidactylus frenatus) feigning death.

by rolling onto their backs and becoming totally motionless (Fig. 7) even if turned right-side up. When left alone for 5-10 min they resumed normal behavior. I also have observed death-feigning in adults when they are handled. Both adults and hatchlings changed color when handled. The adult was dark brown with a prominent pattern but became very pale and almost patternless when captured (Fig. 8). Changes in hatchling color were similarly dark to light when disturbed or light to dark when left alone. I released both the adult and the hatchlings at Nakshatra Van.

Because I found the eggs after deposition, I was unable to determine an incubation period for either species. The incubation period of Calotes versicolor was reported by Daniel $(1983,2002)$ to be $37-47$ days, varying by location and local conditions. Ji et al. (2002) stated that the length of incubation depended on temperature, with eggs requiring 51-60 days to hatch at temperatures under $27-30{ }^{\circ} \mathrm{C}$. In Hemidactylus frenatus, the reported incubation period is 46-62 days (Wilson 2016), with less time required in warmer areas. Wilson (2016) recorded hatchlings measuring $46-60 \mathrm{~mm}$ in total length, whereas the hatchlings in this instance measured only $38 \mathrm{~mm}$ and $31 \mathrm{~mm}$. Whether hatchling size varies in different geographic locations or some other variable is responsible is unknown.

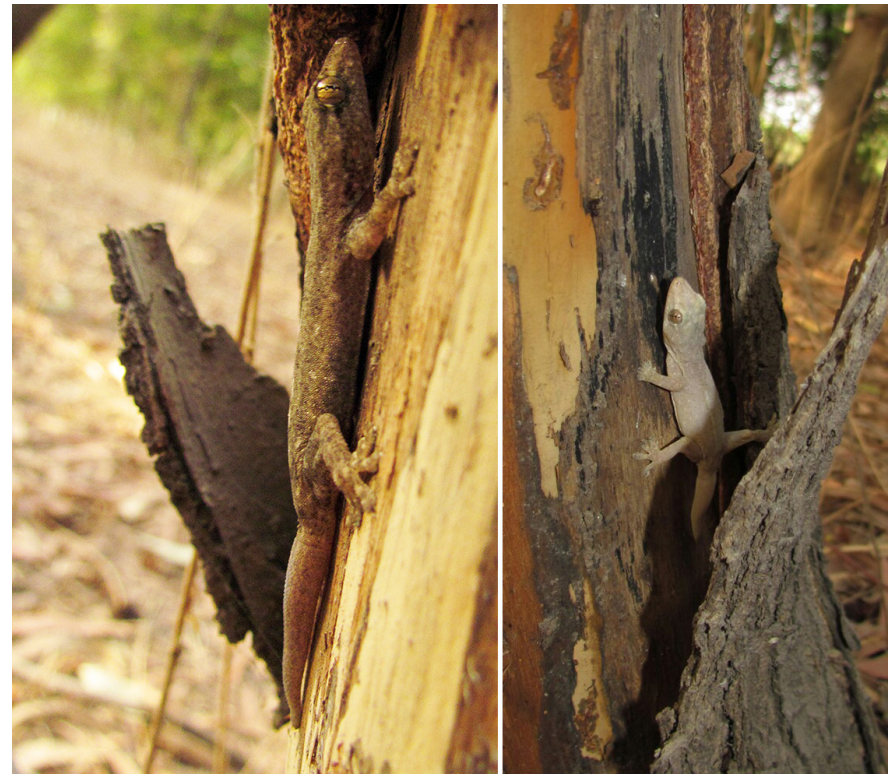

Fig. 8. Color change in a Common House Gecko (Hemidactylus frenatus), dark and patterned prior to handling (left) and pale and very faintly patterned after handling (right).

\section{Acknowledgement}

I thank Smita Ramkumar for her help with the photograph in Fig. 3.

\section{Literature Cited}

Daniel J.C. 1983. The Book of Indian Reptiles. Bombay Natural History Society, Mumbai, India.

Daniel J.C. 2002. The Book of Indian Reptiles. Bombay Natural History Society, Mumbai, India.

Das, A. 2016. Addition to the herpetofauna of Royal Manas National Park, Bhutan, with six new country records. Herpetology Notes 9: 261-278.

Das, I., J.K. Charles, and D.S. Edwards. 2008. Calotes versicolor (Squamata: Agamidae) - A new invasive squamate for Borneo. Current Herpetology 27: 109-112.

Ji, X., Q.-B. Qiu, and C.-H. Diong. 2002. Influence of incubation temperature on hatching success, energy expenditure for embryonic development, and size and morphology of hatchlings in the Oriental Garden Lizard, Calotes versicolor (Agamidae). Journal of Experimental Zoology 292: 649-659.

Parmar, D.S. and S.K. Tank. 2019. Herpetofauna of Veer Narmad South Gujarat University, Surat, India. Reptiles \& Amphibians 26: 21-34.

Wilson, S. 2011. Asian House Geckos. Fact Sheet. Queensland Museum Learning. Queensland Museum, South Brisbane, Queensland, Australia. <www.qm.gov.au>. 